Journal of Sustainability Perspectives

journal homepage: https://ejournal2.undip.ac.id/index.php/isp/

\title{
The Energy Consumption Control as Support to The Environmental and Economic Sustainability of Public Universities
}

\author{
Andrea Pinto Loguercio ${ }^{1,}$, Ruane Fernandes de Magalhães ${ }^{2}$ \\ ${ }^{1,2}$ Sustainability Office, Universidade Federal do Rio Grande do Sul, Av. Paulo Gama 110, 90035-190, Porto \\ Alegre, Brazil \\ *corresponding author: andrea.loguercio@ufrgs.br
}

\section{Article Info}

Received:

15 March 2021

Accepted:

25 May 2021

Published:

1 August 2021

DOI:

Presented in The $6^{\text {th }}$ International (Virtual) Workshop on UI GreenMetric World University Rankings (IWGM 2020)
Abstract Energy consumption at Universities follows specific standards related to the development of its education, research, and extension activities. For these activities' continuity, the supply of energy must have a high level of reliability, without, however, compromising the economic sustainability of the institutions. That is because energy expenditures, in some cases, can be relevant for Universities, especially to public institutions in developing countries, which routinely deal with budget restrictions. On the other hand, energy efficiency and rational energy consumption, have a direct impact on these organizations' environmental sustainability indicators, such as their carbon footprint. In this sense, considering that the Universidade Federal do Rio Grande do Sul faces economic challenges, which often make investments in innovative technologies impossible, we compare strategies to optimize its energy consumption. These strategies should achieve better levels of emission reduction and economic costs related to this resource. Therefore, the objective of this study is to analyze how Public Universities, in developing countries, can optimize their energy consumption, even under budget restrictions. To this end, the results from three strategies adopted by the University, since 2016, to reduce the energy consumption are discussed: (i) increased individual monitoring of consumption points; (ii) optimization and detailed analysis of energy consumption data; and (iii) extensive implementation of reduced summer hours. With the adoption of these practices, it was observed an annual reduction in energy consumption of $6 \%$ and $20 \%$, reaching $33.70 \%$ on average during the summer period. Thus, it was possible to guide the energy policies of the University, which can change consumption patterns, leading to a reduction in greenhouse gas emissions and a better economic equilibrium.

\section{Keyword:}

Energy consumption, reduction of greenhouse gas emission, environmental sustainability, economic sustainability. 


\section{Introduction}

The processes related to the supply of electricity are one of the main responsible for negative impacts on the environment. Concerning the average greenhouse gas emissions in Brazil, energy consumption can trigger up to $21 \%$ of these emissions [1], which are associated with the growing need for the development of society, based on novel production processes and the implementation of technological innovations. In this sense, the urban environment, from its role as a center for activities' integration, is a significant consumer of electricity. For this reason, actions aimed at these regions can constitute, precisely, as relevant opportunities for changes in consumption patterns of energy resources $[2,3]$.

As a way of optimizing energy use, institutions usually employ advanced construction techniques, which are capable of not only promoting high levels of thermal insulation but also the proper management of consumption in buildings [4]. In this context, several agencies and institutions also invest in the generation of renewable energies locally, minimizing demand from more impacting generating sources, such as thermal or oil products. However, it is worth mentioning that these actions, although quite efficient, can have a high cost, especially in developing countries. Consequently, its adoption may compromise the budget of institutions, which routinely deal with severe economic restrictions, such as Public Universities. On the other hand, in Brazil, energy consumption is also the most significant monthly expense of Public Universities, demanding that they be able to reduce their use of electricity, based on adequate actions that do not compromise their budget. The high energy consumption of these institutions also presents another factor of concern, which is related to the environmental impact caused by their activities. Thus, this consumption reduction can support the achievement of equilibrium between lower environmental impacts and the economic viability of the actions taken. The Universidade Federal do Rio Grande do Sul, which is the object of this work aims to be the most sustainable University in Brazil by 2030. Therefore, measures to reduce such impacts can be decisive for this purpose.

Accordingly, this work aims to analyze how Public Universities, especially those in developing countries, can optimize their energy consumption, even under budgetary restrictions. To this end, three different strategies to reduce energy consumption, economically feasible, adopted by the Universidade Federal do Rio Grande do Sul, from 2016, are presented and discussed.

\section{Strategies to reduce electricity consumption}

\subsection{Increasing individual monitoring of consumption points}

As a standard of the electric power concessionaire in the cities of Rio Grande do Sul, where UFRGS is located, most energy measurement points are centralized. UFRGS has four campuses in different regions of the city of Porto Alegre, as shown in Fig. 1 . Therefore, the ideal measurement standard would be that the University had only four monitoring points. However, these points would not support the management of energy consumption at the University, considering the area occupied by the campuses, as well as the consumption specificities resulting from the activities developed in each one of them. 


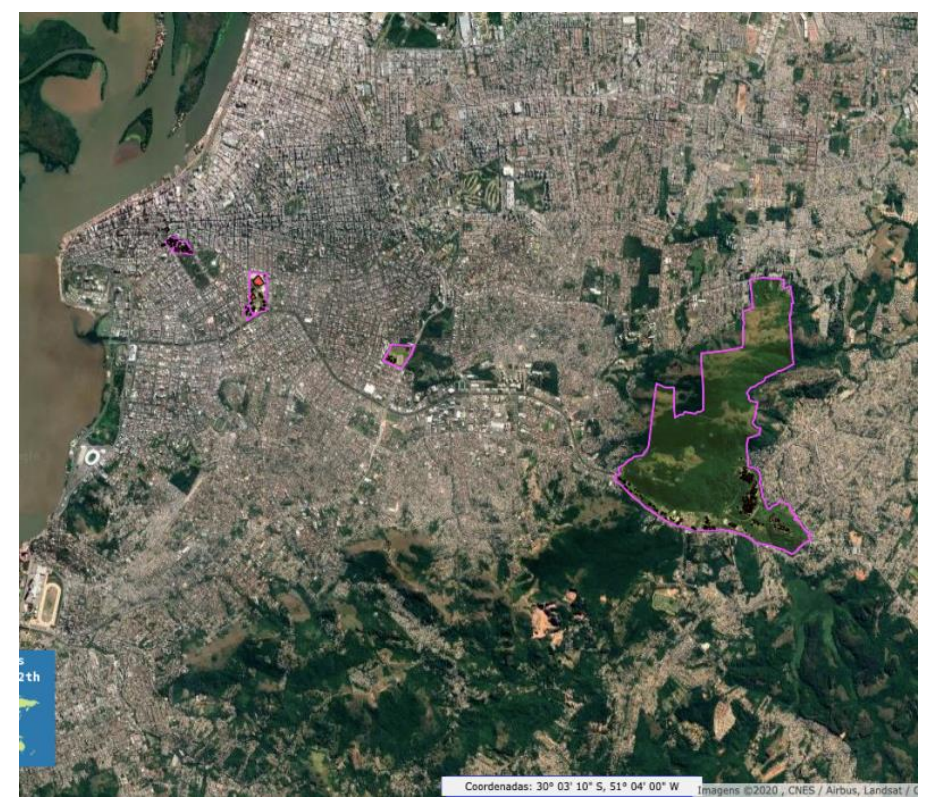

Figure 1. UFRGS campuses in Porto Alegre

To circumvent this barrier and expand control over individual consumption of buildings, or sets of buildings, the University implemented, from 2016, the telemetry program for water and energy consumption monitoring. This program started with some pilot buildings and currently has 30 active measuring points (Fig. 2).

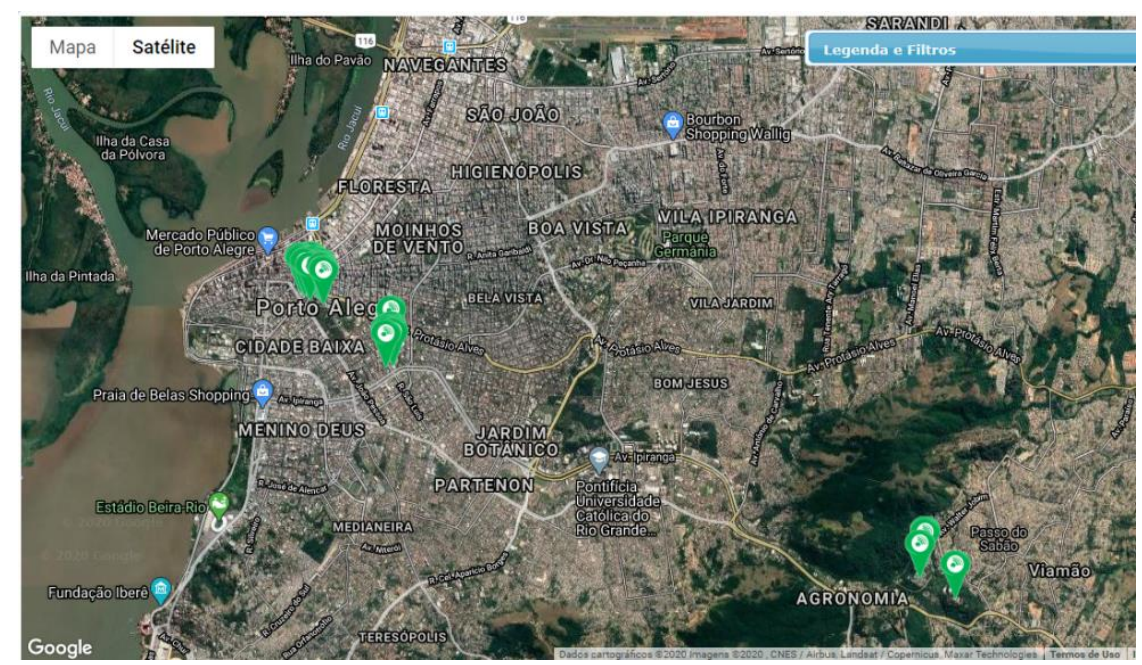

Figure 2. Telemetry points at UFRGS

The telemetry equipment was installed in buildings of the Campus Centro and Campus Saúde, which had energy use reduction projects, making appropriate use of the data collected. The telemetry equipment is located inside the building, close to the power delivery point. Thus, consumption monitoring is performed hourly, providing reports with data on contracted demand, demand consumed, peak consumption hours, days with higher and lower consumption, among other information. These reports are delivered remotely through its system. Besides, telemetry equipment also informs out-of-average consumptions, which helps to identify fault current, reducing the possibility of high use due to technical failures. 
Currently, the UFRGS School of Engineering and the Porto Alegre Sustainable Innovation Zone program (ZISPOA) have established a partnership for the development of energy efficiency studies in the School of Engineering buildings, based on telemetry monitoring. In the Centenary building of the School of Engineering, in addition to energy consumption, water consumption is also monitored. However, currently, new equipment is not being installed, due to the University's budget restrictions.

\subsection{Optimization and detailed analysis of energy consumption data}

Complementarily to the telemetry strategy, the University sought to optimize its analysis of energy consumption data, to provide support for managerial decision-making regarding the control and improvement of the energy efficiency of its built environment. Thus, energy consumption, from the measurement points of the concessionaire and the telemetry, is now monitored monthly and compared with: (i) the same period in three previous years; (ii) the last month, in the same year; and (iii) monthly consumption of buildings with similar types. Also, at each semester, a global analysis is carried out per Campus, comparing to results in previous years.

These analyzes contributed to a better understanding of the main University consumption patterns, as well as the main challenges for their optimization. To strengthen the transparency of the strategies adopted and increase the engagement of the University community in campaigns to reduce energy consumption, all the data collected is available on the UFRGS Sustainability Office website (https://www.ufrgs.br/sustentabilidade). The official social networks of the Sustainability office publicized this information regularly (Fig. 3).

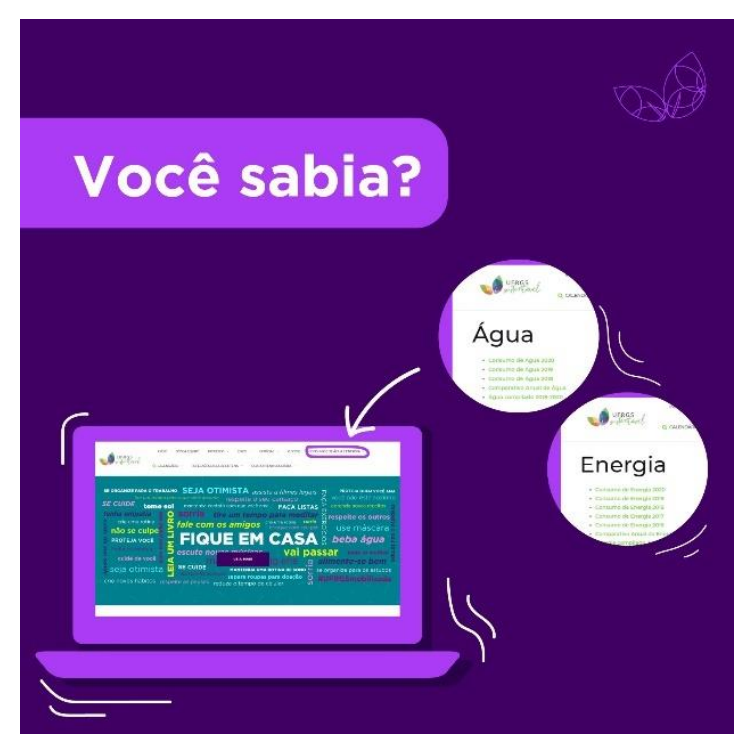

Figure 3. Adversiment of water and energy consumption monitoring (https://instagram.com/ufrgssustentavel)

\subsection{Extensive implementation of reduced summer hours}

The summer period is a relevant contributor to the high consumption of electricity at UFRGS, due to the extensive use of air conditioning. During this period, in Porto Alegre, the average daily temperatures can reach 40 ㅇ $\mathrm{C}$, requiring the use of cooling equipment during the entire workday of servers and the periods of class during morning and evening. 
Some alternatives to minimize consumption in this period would be the investment in the exchange of air conditioning equipment for more efficient models, as well as the building's renovation to improve their thermal insulation. However, these measures exceed the University's budgetary conditions, requiring long-term planning for their implementation. Thus, we adopt measures with lower associated implementation costs to reduce energy consumption during the summer. From 2018 December, the University implemented the "summertime," officially reducing working hours for all departments during the summer period. The reduced hours concentrated activities only in the morning (between 7:30 am and 1:30 pm), thus reducing the energy consumption from air conditioning. In 2018, the strategy was implemented on an experimental basis. With extremely positive results, in 2019, the University deployed the reduced summer hour again, as well as in 2020, inclusive, with a more extended period (from the beginning of December until March).

\section{Results obtained from the strategies implemented}

The monitoring should can to measure the strategies' effects individually, to assess consumption for managerial purposes. This goal was not possible for the first and second strategies adopted due to their interaction with other consumption factors. However, on the strategy of the summer period, in which there are reduced working hours, the monitoring assessed the percentage of reduction obtained when compared to summer periods in years before the strategies implemented. Table 1 presents the maximum and minimum consumption data among the evaluated period, as well as the percentage reduction of consumption verified by the monitoring.

In December, consumption data were compared between 2017 to 2019, while for January and February, the consumption data between 2018 and 2020 were compared, according to periods established for time reduced summer. From these results, the monitoring observed that the average reduction obtained in the period was $33.70 \%$.

Table 1. Percentage reduction in energy consumption

\begin{tabular}{lccc}
\hline Campus & $\begin{array}{c}\text { Maximo } \\
(\mathrm{kWh})\end{array}$ & $\begin{array}{c}\text { Minimum } \\
(\mathrm{kWh})\end{array}$ & $\begin{array}{c}\text { Percentage } \\
\text { reduction }\end{array}$ \\
\hline Centro & 652,467 & 501,053 & $23.21 \%$ \\
Saúde & 515,373 & 356,093 & $30.91 \%$ \\
Olímpico & 65,933 & 22,962 & $65.17 \%$ \\
Vale & $1,460,612$ & $1,109,065$ & $24.07 \%$ \\
Litoral & 45,745 & 34,242 & $25.15 \%$ \\
General UFRGS & $2,681,515$ & $2,112,531$ & $21.22 \%$ \\
\hline
\end{tabular}

UFRG's campuses have different features in their activities and, therefore, their consumption profile is also variable. For example, Campus do Vale is the largest Campus at UFRGS, concentrating activities from different courses, including practical and theoretical classes. Its use is mixed during the summer period, inclusive, reaching a percentage reduction close to that of UFRGS in a general way. On the other hand, the Olympic Campus, which has a wide range of sports activities in its scope, was the place of most considerable consumption reduction over the period evaluated, reaching more than $60 \%$. This reduction was due to the low use of refrigeration equipment, as well as better planning to minimize the activity calendar during the reduced summertime period. 
Concerning annual consumption, results demonstrated a variation between $6 \%$ and $20 \%$ of energy use reduction. This percentage increased in the second edition of the implementation of the strategy (in 2019-2020). The results reflect the cultural change promoted at the University, in which, as the reduced hours become a habit for the academic community, new practices for reducing consumption are incorporated into their routine activities.

The reduced summer hours strategy was extensively investigated and discussed by the University's managers and technicians before its implementation, since it reduced the working hours of staff, without, however, there is a proportional salary reduction. Even so, the strategy was deemed to be adequate and with the potential to reduce University costs, as confirmed in the following years, having been implemented in subsequent academic calendars.

\section{Conclusions}

This work explored the possibilities of strategies for reducing energy consumption in Public Universities, which routinely deal with severe budget restrictions. For this reason, precisely, the reduction of energy consumption is highly relevant for its planning, combining minimization of environmental and economic impacts resulting from its activities. Thus, we present the results obtained from the implementation of three strategies, for this purpose, at UFRGS, from 2016: (i) increased individual monitoring of consumption points; (ii) optimization and detailed analysis of energy consumption data; and (iii) extensive implementation of reduced summer hours.

The results showed that a considerable reduction in consumption patterns is possible based on strategies that integrate adequate monitoring and cultural change for the use of equipment, with the academic community, despite the low investment value for its implementation. In this sense, we believe that strategies that bet on effective cultural change with students, teachers, civil servants, and service providers may be the key for institutions to achieve better levels of efficiency and reduced environmental and economic impacts related to their activities. Therefore, the University intends to expand these strategies, adding new design guidelines for the built environment, aiming at greater energy efficiency. To this end, guidance documents are being implemented for designers to apply these guidelines in retrofits and new works.

\section{References}

1. Angelo, C., Rittl, C., 2018. Análise das emissões brasileiras de gases de efeito estufa e suas implicações para as metas do Brasil. Observatório do clima. Available online at: $<$ http://www.observatoriodoclima.eco.br/wpcontent/uploads/2019/11/OC SEEG Relat orio 2019pdf.pdf>

2. Rosenzweig, C., Solecki, W., 2018. Action pathways for transforming cities. Nature Climate Change, volume 8, pp. 754-756.

3. Leite, C., \& Awad, J. C. M., 2014. Cidades sustentáveis cidades inteligentes. Porto Alegre: Bookman.

4. Amber, K. P., Aslam, M. W., Hussain, S. K., 2015. Electricity consumption forecasting models for administration buildings of the UK higher education sector. Energy and Buildings, volume 90, pp. 127-136. 